\title{
Development and characterization of epoxy syntactic foam filled with epoxy hollow spheres
}

\author{
S. S. Samsudin, Z. M. Ariff, Z. Zakaria, A. A. Bakar \\ School of Materials and Mineral Resources Engineering, Engineering Campus, Universiti Sains Malaysia, 14300 Nibong \\ Tebal, Pulau Pinang, Malaysia
}

Received 10 August 2010; accepted in revised form 24 January 2011

\begin{abstract}
The present study focuses on the development and characterization of epoxy syntactic foam filled with epoxy hollow spheres (ESF/EHoS). The epoxy syntactic foam (ESF) was produced by embedding epoxy hollow spheres (EHoS) into a mixture of epoxy-hardener and $3 \% \mathrm{KOH}$ solution. An innovative approach and simple procedure was implemented in the preparation of the EHoS where expanded polystyrene (EPS) beads were used as initiation material. The EPS beads were coated with the epoxy resin and these coated EPS beads were later cured and post-cured at high temperature which will also shrink the EPS beads thus producing a hollow structure. The physical and compressive properties of the developed ESF were characterized. The progressive collapse of the syntactic foam was monitored in real-time with respect to percentage of strain during a compression test. Results also indicated that the (ESF/EHoS) showed similar deformation pattern with other types of syntactic foams which exhibited the common three regions of deformations.
\end{abstract}

Keywords: mechanical properties, epoxy hollow spheres, syntactic foam, compressive stress

\section{Introduction}

Low density materials with capabilities of withstanding relatively high compressive stresses and deformation as well as damage tolerance have been an attractive research study for several decades. These materials are often used as core materials in sandwich composites for aerospace, automotive, civil as well as marine structural applications [1]. Open-cell foams are normally used for these kinds of properties but these cellular materials always have limitations in their applications because of their low compressive strength and modulus in sandwich structures $[2,3]$. In order to overcome that problem, a class of closed cell foams known as syntactic foams were introduced by dispersing rigid hollow particles in a matrix material. These foams have been widely used in structural applications [47] since the late 1960's and early 1970's [8]. Syn- tactic foams can be classified as closed pore foams, since the porosity in these materials exists in the form of discrete hollow particles. The closed pore structure gives advantages of excellent mechanical properties, higher strength, low density as well as lower moisture absorption compared to the open cell foams [9]. Moreover, the usage of syntactic foams as core material in sandwich structure applications ensures high rigidity and compressive strength of the sandwich structures compared to utilization of other polymeric foams [10]. Several studies on mechanical properties of syntactic foams [7, 11-12] and their sandwich structures can be found in numerous published literature [9, 13-14].

Syntactic foams can be defined as composite materials in which hollow microspheres, or other small hollow particles, are randomly dispersed in a matrix [15]. Basically, there are two types of syntactic

\footnotetext{
${ }^{*}$ Corresponding author, e-mail: zulariff@eng.usm.my
}

(c) BME-PT 
foams: two-phase syntactic foams and three-phase syntactic foams. A two-phase syntactic foam consists of hollow spheres dispersed in a matrix resin [16] either in loose or close-packed structures [17] whereas a three-phase syntactic foam consists of hollow spheres dispersed in a matrix resin containing gaseous voids [18]. Usually, conventional syntactic foams were in two-phase systems. This type of syntactic foam actually has higher density and superior mechanical properties compared to the conventional blown foams, particularly in compression. The lowest practical densities for two-phase syntactic foams containing glass microspheres are limited and lie in the range of $500-600 \mathrm{~kg} / \mathrm{m}^{3}$ [16]. Nevertheless, densities below this value can be achieved only by intentional introduction of air bubbles into the resin thus forming the three-phase foams [16].

Microspheres can be considered versatile fillers compared to other any fillers because these materials can provide a variety of product enhancements and process improvements including low density, improved dimensional stability, increased impact strength, smoother surface finish, greater thermal insulation, easier machinability, faster cycle times, as well as cost savings [19]. Most microspheres are made from rigid shell materials such as polymeric materials (i.e. thermoplastic or thermoset resin) [20], ceramic, carbon, metal and glass [21] to obtain excellent end properties. In some cases, specialized surface treatments such as coatings on the surface of the microspheres will incorporate properties beyond those inherent to the microspheres' materials and construction, allowing the microspheres to be used for specific applications. Coating the microsphere adds new levels of functionality, such as dielectric, magnetic, fluorescent, conductive, thermal imaging properties or simply to improve bonding between the microspheres and the matrix. For example, coatings such as titanium dioxide $\left(\mathrm{TiO}_{2}\right)$ or silver can provide signature management capability where it will control the way in which objects are viewed when imaged using technologies such as radar or infrared imaging [19].

On the other hand, the matrix material binds the microspheres and gives the composite component its shape and determines the quality of its surface finish. Suitable materials can be selected for the matrix materials such as polymers, ceramics or metals [9]. Polymer matrices are commonly used for composites in commercial and high performance aerospace applications. The most widely used polymers are thermoset resins such as epoxy resin. Studies that utilize epoxy resin as the matrix can be found in several works [22-23] and these studies put more focuses on the use of glass hollow microspheres as the dispersed phase [22]. Besides that, most published studies also used and investigated various processing techniques in the production of syntactic foams [24-30]. Some of the literatures described the technique in detail $[31,32]$ and some patented their manufacturing techniques such done by Kim [33] and Meteer and Philipps [34]. Usually, syntactic foams where made by casting [24], pressure infiltration or by a blending method [26].

Generally, syntactic foams possess very good specific properties, especially compressive characteristics, due to the tailorability of their microstructures. Hence, it is important to understand the failure characteristic of syntactic foams during compressive deformation. In this study, epoxy resins were used as the binder while innovative epoxy hollow spheres $(\mathrm{EHoS})$ were developed and used as reinforcing fillers. These materials were combined together using a simple casting technique. The developed EHoS were produced in-house, thus it would provide different approach in the production of syntactic foam compared to previously studied syntactic foams which usually utilized hollow spheres manufactured by established industries [23, 35-37]. Because the matrix and hollow sphere were made from the same materials, the high possibility of achieving good compatibility in the system is an added advantage. Furthermore, the (ESF/EHoS) system is projected to be able to provide new ideas in the development of syntactic foams production.

\section{Experimental}

\subsection{Materials}

D.E.R. 331, a clear liquid epoxy resin, manufactured by DOW Chemical Company (Michigan, U.S.A) was selected for the study. This is a diglycidyl ether of Bisphenol A (DGEBA) based resin with this following characteristics: Epoxide equivalent weight $(\mathrm{g} / \mathrm{eq})$ value of 182-192, viscosity in the range of $11000-14000 \mathrm{mPa} \cdot \mathrm{s}$ and density of $1.16 \mathrm{~g} / \mathrm{ml}$ at $25^{\circ}$ C. D.E.R 331 was chosen as the polymer matrix for the syntactic foam due to wide 
variety of curing agents available to cure the liquid epoxy resin at ambient conditions.

The above mentioned epoxy pre-polymer is an epoxy resin system which is supplied in liquid state and can be hardened by a curing agent when they are mixed in stoichiometric ratio. Clear epoxy hardener 8161 [isophorone diamine (IPD)] was chosen as the curing agent for this study and this chemical was supplied by ZARM Scientific and Supplies Sdn. Bhd (Malaysia). The characteristics of this curing agent are: Amine value of 260-284 mg (KOH)/gm, viscosity in the range of $300-600 \mathrm{mPa} \cdot \mathrm{s}$ and specific gravity of $1.03 \mathrm{~g} / \mathrm{ml}$ at $25^{\circ} \mathrm{C}$. When used with D.E.R 331 resin, the curing agent would provide a reasonably good curing process within 2 to 7 days at ambient temperature.

It is difficult to mix large volumes of hollow spheres in the resin if the viscosity is high. Hence, a diluent was added to reduce the viscosity of the resin mix. To obtain this, Potassium Hydroxide (KOH) aqueous solution with a concentration $3 \%(\mathrm{w} / \mathrm{w})$, was added to the mix to bring down the viscosity of the resin. Besides being the diluent for the system, the $\mathrm{KOH}$ solution also functions as an emulsifier that could be utilized to stabilize another foaming activity (i.e. physical frothing) which was initiated by extensive mixing during the preparation of the resin mix. The $\mathrm{KOH}$ solution was added to the mix in order to stabilize the cellular structure produced by the physical frothing. The $\mathrm{KOH}$ used for this study was obtained from BDH laboratories with lot number $217 \mathrm{C} 179854$ and production code number 29628 5Q.

\subsection{Preparation of epoxy hollow spheres}

A resin mixture comprising of clear epoxy resin (D.E.R 331) and polyamine hardener (clear epoxy hardener 8161) with 2:1 ratio was formulated and mixed by using an in-house fabricated intensive mixer to produce the epoxy system. The EPS beads were later added into the prepared epoxy system in apportioned quantities and were ensured to be fully coated by the epoxy system. These beads were supplied by San Yong Enterprise Sdn. Bhd. with different range of sizes $(3-6.5 \mathrm{~mm})$ and will be used as intermediate materials to develop the EHoS. After that, the epoxy-coated EPS were transferred onto a tray filled with sufficient amount of $\mathrm{CaCO}_{3}$ powder. This step is to ensure that the stickiness problem of the uncured epoxy-coated beads was addressed thus preventing the beads from clumping to each other. These coated EPS beads were then cured in an oven for 15 minutes at $80^{\circ} \mathrm{C}$ and post-cured at $120^{\circ} \mathrm{C}$ for 90 minutes to shrink all the EPS beads inside the epoxy-coated spheres with the intention to produce hollow structures within the spheres. The resultant cured $\mathrm{EHoS}$ were then sprayed with compressed air to remove excess $\mathrm{CaCO}_{3}$ powder on their surface.

\subsection{Preparation of epoxy syntactic foam}

In order to produce the epoxy syntactic foams (ESF), initial preparation of the experimental setup needs to be readily available. The preparation step involves determining the amount of EHoS needed in the next experimental procedure (depending on the size of the spheres) by completely filling a polypropylene mould. This pre-determined amount of EHoS was then removed from the mould and properly put aside. All these initial preparation procedures are essential in ensuring that the mould will be completely filled and because the amount of EHoS was obtained in such a way that would restrict the spheres from floating to the surface during the foam production.

After the preparation steps have been implemented, the mixture for the matrix was prepared by mixing the epoxy resin and the hardener continuously together with the $3 \% \mathrm{KOH}$ solution for about 15 minutes. The amount of $\mathrm{KOH}$ solution was fixed at $40 \%$ by weight with respect to the resin mix. The prepared cured EHoS were then added at regular intervals into the mixture subsequently after the matrix system preparation process has been completed within the duration of 15 minutes. Using such procedure, the uncured matrix compound consisting of EHoS dispersed in the epoxy matrix was achieved. The mixture was then poured evenly into the mould and after the mixture has been transferred into the mould successfully, a constant load with standard weight $(1.2 \mathrm{~kg})$ was placed on top of the mould lid to maintain the EHoS in their welldispersed state. The summary of the initial preparation step and the production of a well dispersed sphere within the mould are illustrated in Figure 1. The mixture was left at room temperature to complete the curing process for 24 hours. The cured composites were then demoulded and cut according to standard dimensions for respective testing after 


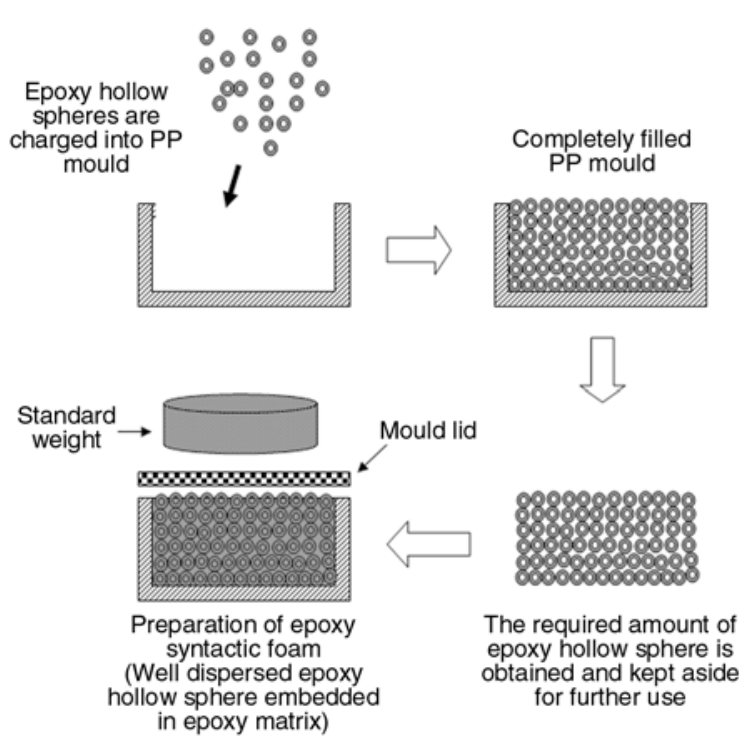

Figure 1. The summary of the initial preparation step and the production of a well dispersed sphere within the mould

Table 1. Composition of ESF/EHoS

\begin{tabular}{|l|}
\hline \multicolumn{1}{|c|}{ Composition } \\
\hline Epoxy Resin \\
\hline Hardener Polyamine \\
\hline $3 \% \mathrm{KOH}$ Aqueous Solution \\
\hline EHoS \\
\hline
\end{tabular}

seven days. Cutting process was done after seven days of the composites were produced due to the typical cure schedule (given by supplier) for epoxy resin with polyamine curing agent is around 2 to 7 days at room temperature. The composition of the $\mathrm{ESF} / \mathrm{EHoS}$ is shown in Table 1.

\subsection{Characterisation}

In this study, the density measurement was made by measuring the mass and volume of regular parallelepiped specimens after removal of surface skin in accordance with standard procedure ASTM D3574. The specimens were cut into approximate dimension $50 \times 50 \times 25 \mathrm{~mm}$ from a uniform area free of irregularities. A Mitutoyo digital vernier caliper (Mitutoyo, Tokyo, Japan) was used to measure the dimension to an accuracy of $0.01 \mathrm{~mm}$. All the specimens were ensured to be undistorted and conditioned in ambient room condition for 24 hours prior to mass and volume determination. The specimens were weighed on a Precisa digital analytical balance (Precisa Gravimetrics AG, Dietikon,Switzerland), model XT 220A to an accuracy of $0.0001 \mathrm{~g}$. An average value determined from 5 samples was used as the density of the prepared foam. A digital image of the syntactic foam morphology was captured using a flatbed scanner. The sample image were then captured as to qualitatively assess and then further analyzed using Image $J$ software to determine the spheres' cell sizes and their distribution within the matrix. In this method, the cells were selected randomly from the digital image and the image was then manually edited to highlight all cells boundaries at a set detection level of dark shades. Once this optimization is completed, thirty cells were counted from the selected regions of the observed digital images. This counting procedure was performed manually and the software was utilized to further conduct the statistical analysis such as determination of average cell size and cell distribution. Besides these measurements, the wall thickness of the produced EHoS was also assessed using similar image analysis facilities (see Figure 2). The amount of $\mathrm{CaCO}_{3}$ embedded in the sphere wall was measured by placing a substantial amount of the EHoS in a furnace set at $600^{\circ} \mathrm{C}$ for 1 hour. This procedure burnt off the epoxy wall, and the remaining unburned portion was taken as the amount of $\mathrm{CaCO}_{3}$ present in the sphere. The result indicated that the EHoS wall contained approximately $19 \% \mathrm{CaCO}_{3}$.

Compression test were carried out using a TestResources universal testing machine model Bi-00-71 (Shakopee, MN, USA). The samples were prepared in accordance with ASTM D3575, and at least four samples were tested. A crosshead speed of $6 \mathrm{~mm} / \mathrm{min}$ was used to gradually monitor and record real-time changes that occurred during the compression test.

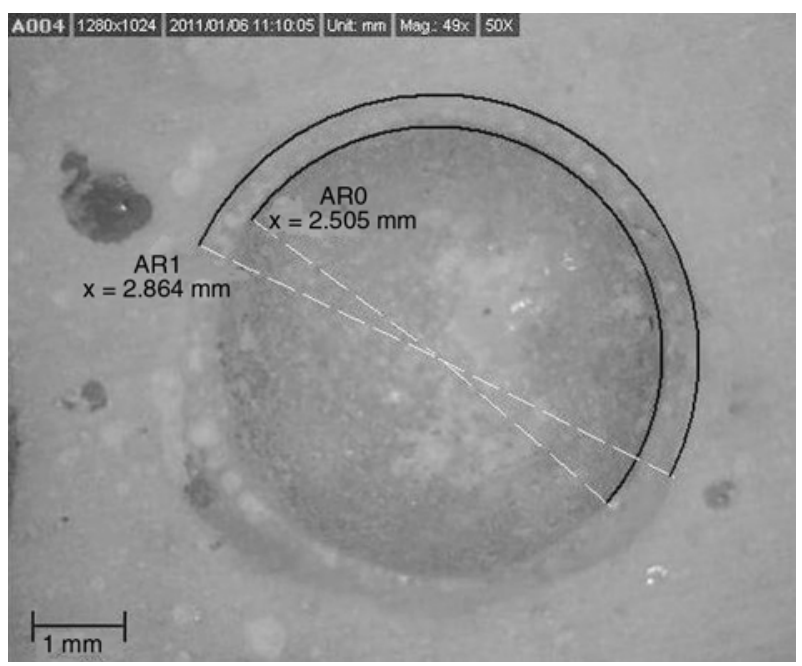

Figure 2. Digital image of a single EHoS showing its wall thickness 


\section{Results and discussion}

Figure 3a shows a typical microstructure of the $\mathrm{ESF} / \mathrm{EHoS}$ prepared in this study. Two types of porosity appeared in this material, which were contributed by the hollow spheres and matrix as shown in Figure $3 b$ at high magnification. The hollow sphere porosity can be controlled by selecting the type and the size of hollow sphere. However, the matrix porosity could be attributed to air entrapment, which resulted in the formation of voids within the matrix during the mixing and coating procedure, as shown in Figure 2. Although an increase in porosity would undermine the mechanical properties the foam system, it can also be considered an advantage in that it can be manipulated to adjust the overall density and properties of the system. Table 2 shows several characteristics and properties of the produced ESF/EHoS.

The average density of the syntactic foam system was $566 \mathrm{~kg} / \mathrm{m}^{3}$ and this density was lower than the experimental result for control epoxy matrix without $\operatorname{EHoS}\left(1050 \mathrm{~kg} / \mathrm{m}^{3}\right)$ and commercial epoxy matrix without EHoS $\left(1160 \mathrm{~kg} / \mathrm{m}^{3}\right)[3,36]$. This lower density was due to the utilization of the EHoS, which can effectively reduce the density of the materials and also provide a way of reducing the production cost which was attributed to the low price of the EPS bead templates compare to the

Table 2. Properties of the ESF/EHoS

\begin{tabular}{|l|c|}
\hline & Properties \\
\hline Compressive strength $[\mathrm{MPa}]$ & 19.756 \\
\hline Modulus $[\mathrm{MPa}]$ & $187.0 \pm 0.7$ \\
\hline Cell size $[\mathrm{mm}]$ & Size range $\sim 3-6$ \\
\hline Density $\left[\mathrm{kg} / \mathrm{m}^{3}\right]$ & $566 \pm 9$ \\
\hline
\end{tabular}

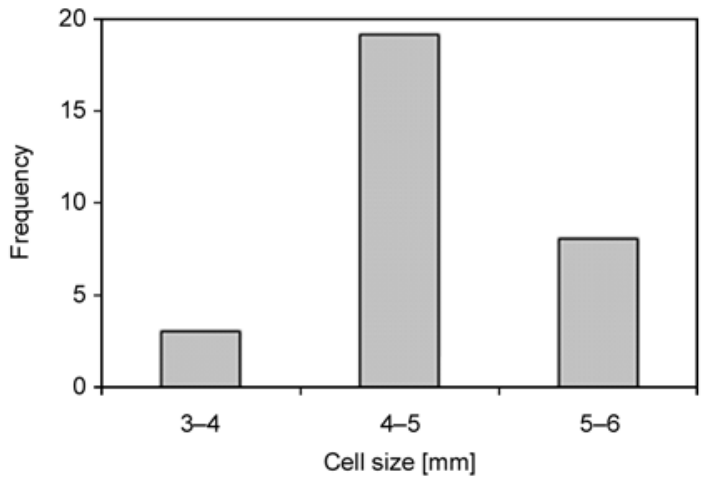

Figure 4. Distribution of EHoS size in the produced syntactic foam

other types hollow spheres available in the market. The cell sizes and their distribution are illustrated in Figure 4 where 30 readings were taken to ensure a good representation of the overall cell morphology. It can be seen that the cell sizes of the EHoS was quite close to one another and that cell wall thicknesses for the EHoS were nearly the same which is around $0.40 \mathrm{~mm}$.

The evidence of progressive collapse and the stressstrain curve for the ESF/EHoS are shown in Figure 5. The images in Figure 6a-d were taken from one sample with the lowest strength from the four samples that were subjected to compression test, in which complete crushing and collapse of the EHoS can be seen all over the side surface of the test specimen. The compressive behavior displayed by the syntactic foam was comparable to other syntactic foam systems, which utilized other thermoset matrix and glass microspheres as their constituents [2]. The initial drop in stress at $10 \%$ compressive strain can be related to the occurrence of crack initi-

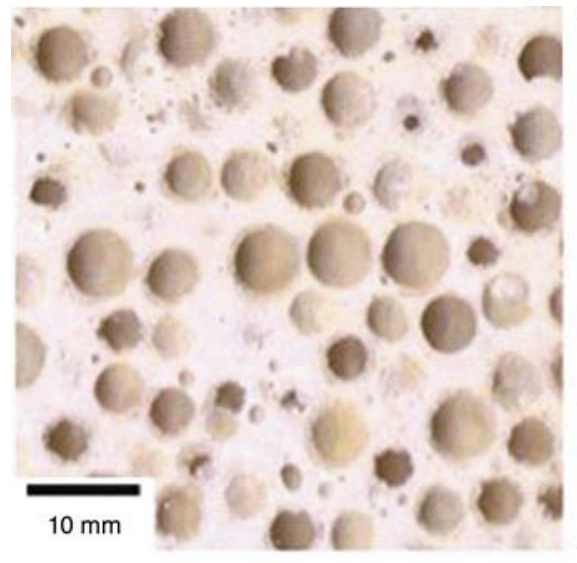

a)

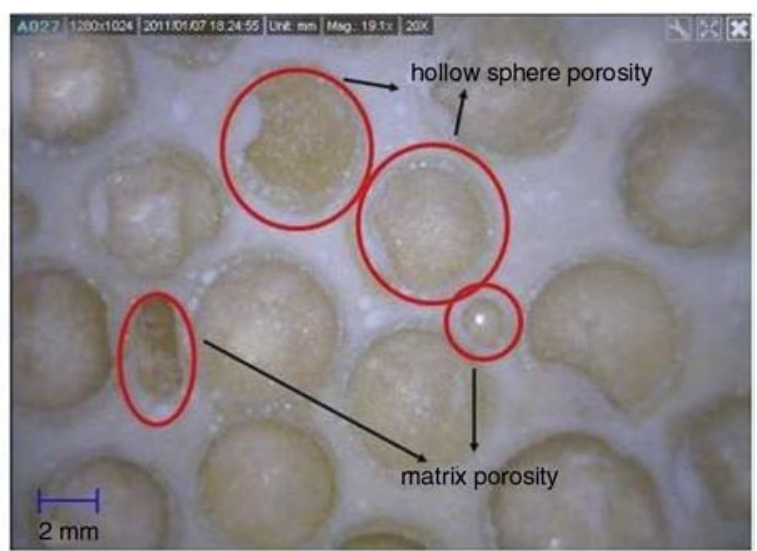

b)

Figure 3. (a) Low magnification image of the ESF/EHoS (b) High magnification image of the ESF/EHoS showing hollow spheres porosity and matrix porosity 


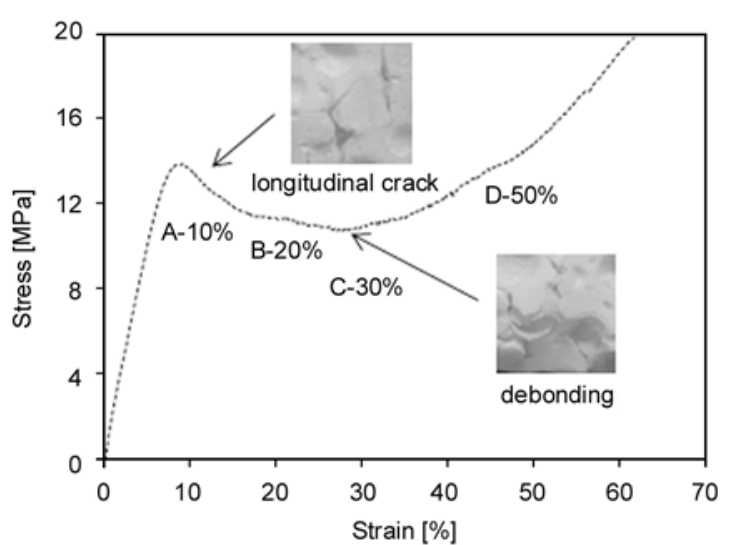

Figure 5. Representative compressive stress-strain curve for the $\mathrm{ESF} / \mathrm{EHoS}$

ation in the matrix as can be seen from the progressive cell collapse image included in Figure 6 [35]. At this stage, compression of the material resulted in a filling up of the matrix porosity due to the rupture of the porous feature. Further compression caused the formation of a shear crack in the longitudinal direction (i.e. the direction of compression) [3]. The slope then leveled in the region of $20 \%$ strain (b). During this stage, the longitudinal crack grew and the crushing of the EHoS was initiated. At this stage, further compression of the material resulted in more filling up of the matrix porosity due to the rupture of the porous feature. The extent of plateau region continued up till 30\% strain (c) and the fracture mechanism in this region involved crushing of the EHoS, and similar observations were also reported by Kim and Plubrai [29].

Besides sphere crushing, the failure of EHoS can also be attributed to debonding (i.e. interfacial fracture between the matrix and EHoS) at the surfaces of the EHoS. However, the presence of voids in the EHoS limits the occurrence of debonding and promoted a higher failure mechanism through the rupture of the sphere wall because such fracture is faster than debonding. When a significant portion of the EHoS had been crushed, further loading caused densification of the foam [38], which was observed exceeding 35\% strain as depicted in Figure 6 . Above $50 \%$ (D) strain, the syntactic foam system failed completely.

\section{Conclusions}

The development of EFS/EHoS syntactic foams and their compressive properties were investigated in the present study. The most crucial advantages of

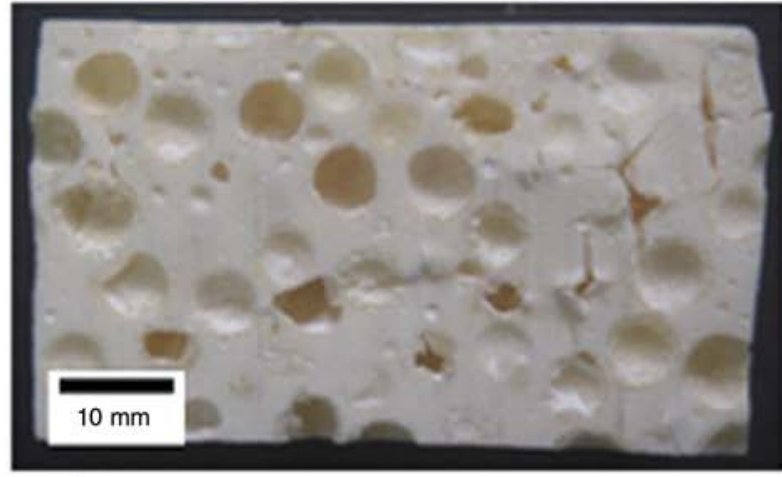

a)

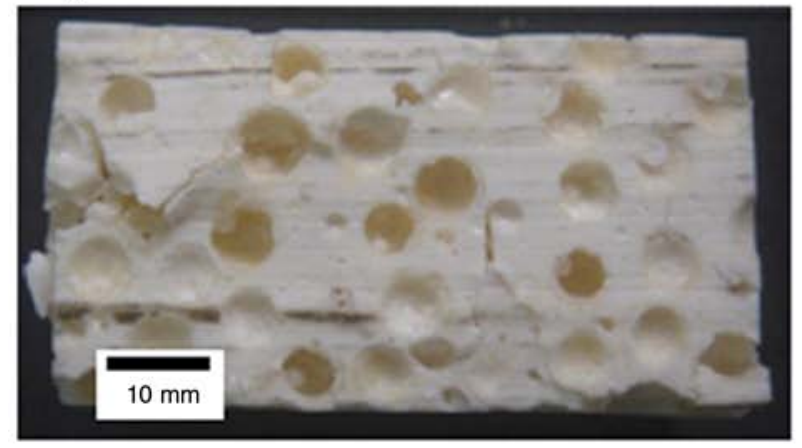

b)

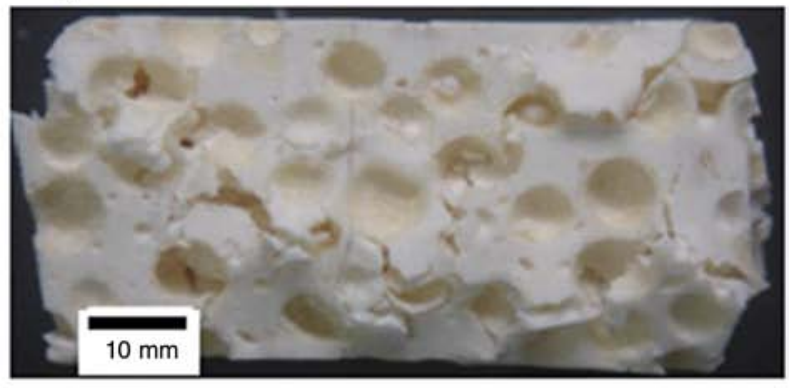

c)

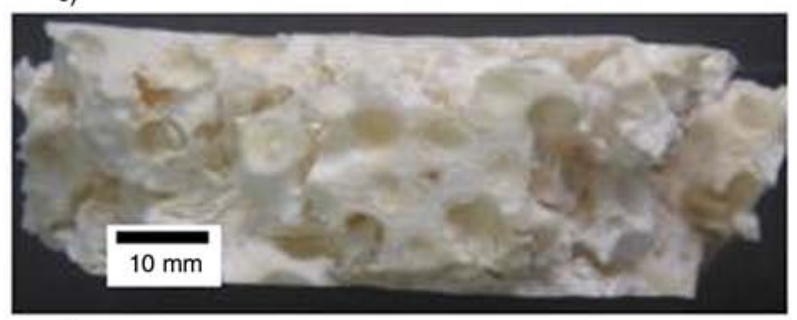

d)

Figure 6. Deformation development of ESF/EHoS at (a) $10 \%$; (b) $20 \%$; (c) $30 \%$; (d) $50 \%$ of compression

this syntactic foam are due to its simple production method and low cost production strategy because it does not utilize any expensive specialized equipment during its processing procedure which can be implemented at room temperature. The prepared EHoS showed great potential in replacing glass microspheres, which have been extensively used in many previous works. We found that the produced 
syntactic foam had relatively high compressive modulus and compressive strength, and thus has the potential to be used in various engineering applications. Moreover, further studies regarding the wall thickness differences could be considered in the future to enhance utilization of these epoxy hollow spheres in their desired applications.

\section{Acknowledgements}

The authors would like to acknowledge the financial support from the Malaysian Ministry of Higher Education through the Fundamental Research Grant Scheme (Grant reference no. 203/PBAHAN/6071172).

\section{References}

[1] Tagliavia G., Porfiri M., Gupta N.: Vinyl ester-glass hollow particle composites: Dynamic mechanical properties at high inclusion volume fraction. Journal of Composite Materials, 43, 561-582 (2009). DOI: $10.1177 / 0021998308097683$

[2] Gupta N., Ye R., Porfiri M.: Comparison of tensile and compressive characteristics of vinyl ester/glass microballoon syntactic foams. Composites Part B: Engineering, 41, 236-245 (2009). DOI: $10.1016 /$ j.compositesb.2009.07.004

[3] Gupta N., Ye R., Porfiri M.: Characterization of vinyl ester-glass microballon syntactic foams for marine applications. in: 'Proceeding of $22^{\text {nd }}$ Annual Technical Conference of American Society for Composites. Seattle, USA' paper 072 (2008).

[4] Sauvant-Moynot V., Gimenez N., Sautereau H.: Hydrolytic ageing of syntactic foams for thermal insulation in deep water: Degradation mechanisms and water uptake model. Journal of Materials Science, 41, 4047-4054 (2006).

DOI: $10.1007 / \mathrm{s} 10853-006-7618-0$

[5] Gupta N., Woldesenbet E.: Hygrothermal studies on syntactic foams and compressive strength determination. Composite Structures, 61, 311-320 (2003). DOI: 10.1016/S0263-8223(03)00060-6

[6] Gupta N., Priya S., Islam R., Ricci W.: Characterization of mechanical and electrical properties of epoxyglass microballoon syntactic composites. Ferroelectrics, 345, 1-12 (2006).

DOI: $10.1080 / 00150190601018002$

[7] Woldesenbet E., Peter S.: Volume fraction effect on high strain rate properties of syntactic foam composites. Journal of Materials Science, 10, 3065-3074 (2007).

DOI: $10.1007 / \mathrm{s} 10853-008-3065-4$

[8] Malloy R. A., Hudson J. A.: Handbooks of composites reinforcement. VCH Publishers, New York (1993).
[9] Gupta N., Woldesenbet E.: Microballoon wall thickness effects on properties of syntactic foams. Journal of Cellular Plastics, 40, 461-482 (2004).

DOI: $10.1177 / 0021955 X 04048421$

[10] Gupta N., Woldesenbet E., Kishore: Compressive fracture features of syntactic foams-Microscopic examination. Journal of Materials Science, 37, 3199-3209 (2002).

DOI: 10.1023/A:1016166529841

[11] Gladysz G. M., Chawla K. K.: Syntactic and composite foams: Proceedings of an engineering conferences international (ECI) conference. Journal of Materials Science, 41, 3959-3960 (2006).

DOI: $10.1007 / \mathrm{s} 10853-006-7570-\mathrm{Z}$

[12] Choqueuse D., Davies P.: Ageing of composites in underwater applications. in 'Ageing of composites' (eds.: Martin R.) Woodhead Publishing, Cambridge, 467-498 (2008).

[13] Devi K. A., John B., Nair R. C. P., Ninan K. N.: Syntactic foam composites of epoxy-allyl phenol-bismaleimide ternary blend - Processing and properties. Journal of Applied Polymer Science, 105, 3715-3722 (2007).

DOI: $10.1002 / a p p .26316$

[14] Banhart J.: Manufacture, characterisation and application of cellular metals and metal foams. Progress in Materials Science, 46, 559-632 (2001). DOI: $10.1016 / \mathrm{S} 0079-6425(00) 00002-5$

[15] Puterman M., Narkis M., Kenig S.: Syntactic foams I. Preparation, structure and properties. Journal of Cellular Plastics, 16, 223-229 (1980). DOI: $10.1177 / 0021955 X 8001600403$

[16] Narkis M., Puterman M., Kenig S.: Syntactic foams II. Preparation and characterization of three-phase systems. Journal of Cellular Plastics, 16, 326-330 (1980). DOI: $10.1177 / 0021955 X 8001600603$

[17] Narkis M., Gerchcovich M., Puterman M., Kenig S.: Syntactic foams III. Three-phase materials produced from resin coated microballoons. Journal of Cellular Plastics, 18, 230-232 (1982). DOI: $10.1177 / 0021955 X 8201800402$

[18] Landrock A. H.: Handbooks of plastics foams. Noyes Publications, New Jersey, (1976).

[19] Belle B. V.: Advances in high-temperature syntactic foam technology for offshore systems. in '2002 Offshore Technology Conference. Houston, USA' Paper 14120-MS (2002). DOI: $10.4043 / 14120-\mathrm{MS}$

[20] Capela C., Costa J. D., Ferreira J. A. M.: Test conditions effect on the fracture toughness of hollow glass micro-sphere filled composites. Strain, 44, 141-146 (2008).

DOI: $10.1111 / \mathrm{j} .1475-1305.2007 .00357 . \mathrm{x}$ 
[21] Wouterson E. M., Freddy Y., Boey C., Hu X., Wong SC.: Specific properties and fracture toughness of syntactic foam: Effect of foam microstructures. Composites Science and Technology, 65, 1840-1850 (2005). DOI: $10.1016 /$ j.compscitech.2005.03.012

[22] Lin T. C., Gupta N., Talalayev A.: Thermoanalytical characterization of epoxy matrix-glass microballoon syntactic foams. Journal of Materials Science, 44, 1520-1527 (2009).

DOI: $10.1007 / \mathrm{s} 10853-008-3074-3$

[23] Yung K. C., Zhu B. L., Yue T. M., Xie C. S.: Preparation and properties of hollow glass microsphere-filled epoxy-matrix composites. Composites Science and Technology, 69, 260-264 (2009).

DOI: 10.1016/j.compscitech.2008.10.014

[24] Daoud A.: Synthesis and characterization of novel ZnAl22 syntactic foam composites via casting. Materials Science and Engineering A, 488, 281-295 (2008). DOI: 10.1016/j.msea.2007.11.020

[25] Rohatgi P. K., Guo R. Q., Iksan H., Borchelt E. J., Asthana R.: Pressure infiltration technique for synthesis of aluminum-fly ash particulate composite. Materials Science and Engineering A, 244, 22-30 (1998). DOI: 10.1016/S0921-5093(97)00822-8

[26] Orbulov I. N., Dobranszky J., Nemeth A.: Microstructural characterisation of syntactic foams. Journal of Materials Science, 44, 4013-4019 (2009).

DOI: $10.1007 / \mathrm{s} 10853-009-3552-2$

[27] Andersen O., Waag U., Schneider L., Stephani G., Kieback B.: Novel metallic hollow sphere structures. Advanced Engineering Materials, 2, 192-195 (2000). DOI: 10.1002/(SICI)1527-2648(200004)2:4<192::AIDADEM192>3.0.CO;2-\#

[28] Verweij H., With G., Veeneman D.: Hollow glass microsphere composites: Preparation and properties. Journal of Materials Science, 20, 1069-1078 (1985). DOI: $10.1007 / \mathrm{BF} 00585751$

[29] Kim H. S., Plubrai P.: Manufacturing and failure mechanisms of syntactic foam under compression. Composites Part A: Applied Science and Manufacturing, 35, 1009-1015 (2004).

DOI: $10.1016 /$ j.compositesa.2004.03.013
[30] Nijenhuis K., Addink R., Vegt A. K.: A study on composites of nylon-6 with hollow glass microspheres. Polymer Bulletin, 21, 467-474 (1989).

DOI: $10.1007 / \mathrm{BF} 00271969$

[31] Ramachandara M., Radhakrishna K.: Synthesismicrostructure-mechanical properties-wear and corrosion behavior of an Al-Si (12\%)- flyash metal matrix composite. Journal of Materials Science, 40, 59895997 (2005).

DOI: $10.1007 / \mathrm{s} 10853-005-1303-6$

[32] Ramachandra M., Radhakrishna K.: Effect of reinforcement of flyash on sliding wear, slurry erosive wear and corrosive behavior of aluminium matrix composite. Wear, 262, 1450-1462 (2007).

DOI: $10.1016 /$ j.wear.2007.01.026

[33] Kim H. S.: Method for forming syntactic foams. U.S. Patent 2008/0233384 A1, USA (2008).

[34] Meteer C. L., Philipps T. E.: Syntactic foam core material for composite structures. U.S. Patent 5888642 , USA (1999).

[35] Caeti R., Gupta N., Porfiri M.: Processing and compressive response of functionally graded composites. Materials Letters, 63, 1964-1967 (2009). DOI: $10.1016 /$ j.matlet.2009.06.024

[36] Gupta N., Nagorny R.: Tensile properties of glass microballoon-epoxy resin syntactic foams. Journal of Applied Polymer Science, 102, 1254-1261 (2006). DOI: 10.1002/app.23548

[37] Karthikeyan C. S., Sankaran S., Kishore: Elastic behaviour of plain and fibre-reinforced syntactic foams under compression. Materials Letters, 58, 995-999 (2004).

DOI: $10.1016 /$ j.matlet.2003.08.012

[38] Li P., Petrinic N., Siviour C. R., Froud R., Reed J. M.: Strain rate dependent compressive properties of glass microballoon epoxy syntactic foams. Materials Science and Engineering: A, 515, 19-25 (2009). DOI: $10.1016 /$ j.msea.2009.02.015 